\title{
Experimental Study on the Absorption of Toluene from Exhaust Gas by Paraffin/Surfactant/Water Emulsion
}

\author{
Ping Fang, Zi-jun Tang, Xiong-bo Chen, Zhi-xiong Tang, Ding-sheng Chen, \\ Jian-hang Huang, Wen-hao Zeng, and Chao-ping Cen \\ South China Institute of Environmental Sciences, Ministry of Environmental Protection, Guangzhou 510655, China \\ Correspondence should be addressed to Chao-ping Cen; cenchaoping@scies.org
}

Received 20 September 2016; Accepted 17 November 2016

Academic Editor: Esperanza Pavón

Copyright (c) 2016 Ping Fang et al. This is an open access article distributed under the Creative Commons Attribution License, which permits unrestricted use, distribution, and reproduction in any medium, provided the original work is properly cited.

\begin{abstract}
A new paraffin/surfactant/water emulsion (PSW) for volatile organic compounds (VOCs) controlling was prepared and its potential for VOCs removal was investigated. Results indicated that PSW-5 (5\%, v/v) provided higher toluene absorption efficiency (90.77\%) than the other absorbents used. The saturation pressure, Henry's constant, and activity coefficient of toluene in PSW-5 were significantly lower than those in water, and toluene solubility $\left(1.331 \mathrm{~g} \cdot \mathrm{L}^{-1}\right)$ in the PSW-5 was more than 2.5 times higher than the value in water. Several factors potentially affecting the toluene absorption efficiency were systematically investigated. The results suggested that concentration and $\mathrm{pH}$ of PSW, absorption temperature, and gas flow rate all had a strong influence on the toluene absorption, but the inlet concentration of toluene had little effect on the toluene absorption. There were different absorbing performances of PSW-5 on different VOCs, and the ketones, esters, and aromatics were more easily removed by the PSW-5 than the alkanes. Regeneration and reuse of the PSW were possible; after 3 runs of regeneration the absorption efficiency of PSW-5 for toluene also could reach $82.42 \%$. So, the PSW is an economic, efficient, and safe absorbent and has a great prospect in organic waste gas treatment.
\end{abstract}

\section{Introduction}

In recent years, volatile organic compounds (VOCs), due to their high volatility, reactivity, and toxicity to humans and environment, have received increasing attention as the air pollutants of serious concern [1]. In China, VOCs are classified as major contributors to air pollution, because they are the precursors of ground-level ozone and fine particles and contribute to ground level of smog formation, toxic and carcinogenic human health effects, and so on [2,3]. Industrial source is considered as the largest source of anthropogenic VOCs emissions. With the rapid development of urbanization and industrialization in China, the VOCs emissions increase rapidly. It was reported that China's industrial nonmethane VOCs emissions had increased by 11.6 times at an average annual rate of $8.5 \%$ from 1.15 million tons in 1980 to 13.35 million tons in 2010 [4], and it was estimated that industrial nonmethane VOCs emissions were more than 16.37 million tons in 2014. Now, the annual VOCs emission amount has exceeded that of $\mathrm{NOx}$ or $\mathrm{SO}_{2}$, and VOCs contamination has become a serious problem in China. In recent years, the Chinese government attaches great importance to VOCs pollution control. Accordingly, various environmental laws and regulations for the prevention and control of VOCs pollution have been enacted. So, in order to meet the stringent environment regulations, VOCs emission from industry must be effectively controlled.

Many researches and engineering efforts are being explored to control VOCs emissions. Cleaner production technology and upstream process improvement can lead to a decrease in the VOCs emission, but in most cases it cannot achieve the VOCs emission standard. So, it is necessary to set up an air treatment process. Presently, various technologies have been developed to remove VOCs from exhaust gas and basically classified into two groups based on recovery and destruction [5]. Absorption [6], adsorption [7], membrane separation [8], and condensation [9] are classified as recovery techniques whereas thermal or catalytic oxidation [10], biological treatment [11], plasma technology [12], advanced oxidation process $[13,14]$, and biofiltration [15] are considered 
as destructive ones. They all have many advantages and limitations, and different technology has different application conditions, but no single technology can be used in all cases.

Among them, absorption is generally considered to be a simple, economical, safe, and effective technology for removing medium/high concentration VOCs (VOCs concentrations from 500 to $5000 \mathrm{ppm}$ ) from exhaust gas with a absorption efficiency of $95-98 \%[16,17]$. The choice of a suitable absorbent is the key to successful application of the absorption. A suitable absorber should have the following characteristics [18]: high absorption capacity of VOCs, highboiling and low vapor pressure, a low viscosity and a high diffusion coefficient, safety and no toxicity, and a low cost. According to aforesaid criteria and the principle of similarity and intermiscibility, water is widely used to absorb hydrophilic VOCs such as alcohols and ketones [19], and high-boiling organic absorbents, including silicon oil [20], cutting oil [21], fresh or waste vegetable oil and lubricant oil [16], poly(dimethylsiloxane) [22], di(2-ethylhexyl)adipate $[3,23]$, and surfactant solution [24], are used to absorb hydrophobic VOCs such as aromatic, halogenated hydrocarbons. Most of VOCs from industry exhaust gas are hydrophobic, which correspond to low solubility in water, but high solubility in high-boiling organic absorbents. However, organic absorbents' high viscosity and security risk hinder their application [25]. In order to overcome the disadvantages of organic absorbent, emulsions such as surfactant/water [26] and water/oil emulsions [2] have been developed. They have low viscosity and high security and can remove VOCs efficiently. However, there is limited information on the absorption of VOCs using oil/surfactant/water emulsion in the literatures.

In this study, paraffin was used to prepare emulsion, due to its high absorption capacity of VOCs, high stability, low cost (about $900 \$ \cdot$ ton $^{-1}$ in China), degradability, and no toxicity. Finally, a new paraffin/surfactant/water emulsion for VOCs controlling was prepared. Its potential for VOCs removal was investigated, and toluene was used as a typical industrial organic waste gas. A sequence of experiments was carried out in order to evaluate the influence of different operational parameters on VOCs absorption efficiency in a packed bed bubble column reactor, and the regeneration and reuse of used absorbent were studied. Meanwhile, the solubility, saturation pressure, Henry's constant, and activity coefficient of toluene in the emulsion were also calculated.

\section{Experimental Setup}

2.1. Materials. Standard gases included air (99.999\%), $\mathrm{H}_{2}$ (99.999\%), and $\mathrm{N}_{2}$ (99.999\%); they were the products of the Gas Co., Ltd., of Zhuo Zheng, Guangzhou, China. Benzene, toluene, xylene, ethyl acetate, hexane, acetone, and paraffin were purchased from Guangzhou Chemical Reagent Factory. Polyethylene glycol, dimethyl sulfoxide (DMSO), tween 80 , and span 80 were purchased from Tianjin Damao Chemical Reagent Factory. All reagents were of analytical grade and used without purification. Deionized water and tap water were applied to prepare the emulsion and the absorption solution, respectively.

\subsection{Preparation of Emulsion and Absorption Solution}

Preparation of Emulsion. (1) Mix tween 80 and span 80 with mass ratio of $1: 0.4$ and stir to prepare a combined surfactant with a HLB value of 12. (2) A certain amount of combined surfactant was dissolved in a certain amount of paraffin, then adding a certain amount of deionized water to the surfactant/paraffin mixed solution under the conditions of stirring to prepare paraffin/surfactant/water emulsion (hereinafter referred to as PSW). The composition ratio of emulsion is paraffin : surfactant $:$ water $=9: 1: 4(\mathrm{w}: \mathrm{w}: \mathrm{w})$, and the emulsion is a milky white and a little sticky liquid. The emulsion will be used to prepare the VOCs absorption solution.

Preparation of Absorption Solution. $50 \mathrm{ml}$ of emulsion was dissolved in $950 \mathrm{ml}$ of tap water to make the solution that was used as VOCs absorption solution in this study (hereinafter referred to as PSW-5).

2.3. Experimental Setup. Figure 1 shows the schematic diagram of the experimental apparatus including VOC generator, organic waste gas simulation system, absorption reactor, absorption solution regeneration system, and online gas analysis system. The absorption reactor was heated with a temperature-controlled heating belt to ensure a constant absorption temperature.

As shown in Figure 1, air was obtained from cylinder and divided into four parts: part of it was sent directly into the gas mixing bottle, part of it was sent to pass through a toluene generator to carry out precalibrated toluene to form waste gas containing toluene, and left two parts were sent to pass through a benzene or other VOC generator to carry out precalibrated benzene or other VOC to form organic waste gases, respectively. Each part of air was metered through mass flow controllers (Beijing seven-star electronics Co., Ltd., China), and 4 kinds of gas finally mixed in the gas mixing bottle to form the simulated organic waste gas. The mass flow controller could be closed when a gas was not used. In this study the total flow rate of gas including toluene or other VOC $\left(Q_{\text {gas }}\right)$ was fixed to $1000 \mathrm{ml} \cdot \mathrm{min}^{-1}$. The toluene concentrations in the inlet gas were varied in the range from 500 to $5200 \mathrm{mg} \cdot \mathrm{m}^{-3}$. The toluene and other VOCs were generated from liquid organic reagents inside the VOC generators, cooled in a low temperature circulating water bath (THX2005, Ningbo Tianheng Instrument Factory) with 30$60 \mathrm{ml} \cdot \mathrm{min}^{-1}$ air as carrier gas. The concentration of toluene or other VOC was changed by altering cooling temperature and the flux of carrier gas.

The experiments were performed in a countercurrent packed bed bubble column reactor made of borosilicate glass ( $4.5 \mathrm{~cm}$ in diameter and $90 \mathrm{~cm}$ in length). The column was packed with ceramic Raschig rings $(12.5 \mathrm{~mm}$ in diameter and $12.5 \mathrm{~mm}$ in length); packed height was $30 \mathrm{~cm}$. In each typical experiment, the temperature of water bath was adjusted to the constant value $\left(5^{\circ} \mathrm{C}\right)$, and then $1 \mathrm{~L}$ absorption solution was put into the reactor. After $1 \mathrm{~h}$, when the temperature of solution $\left(25^{\circ} \mathrm{C}\right)$ and water bath $\left(5^{\circ} \mathrm{C}\right), Q_{\text {gas }}$ and VOCs concentration were stable; then the gas mixture continuously flowed through the absorption reactor. The concentrations 


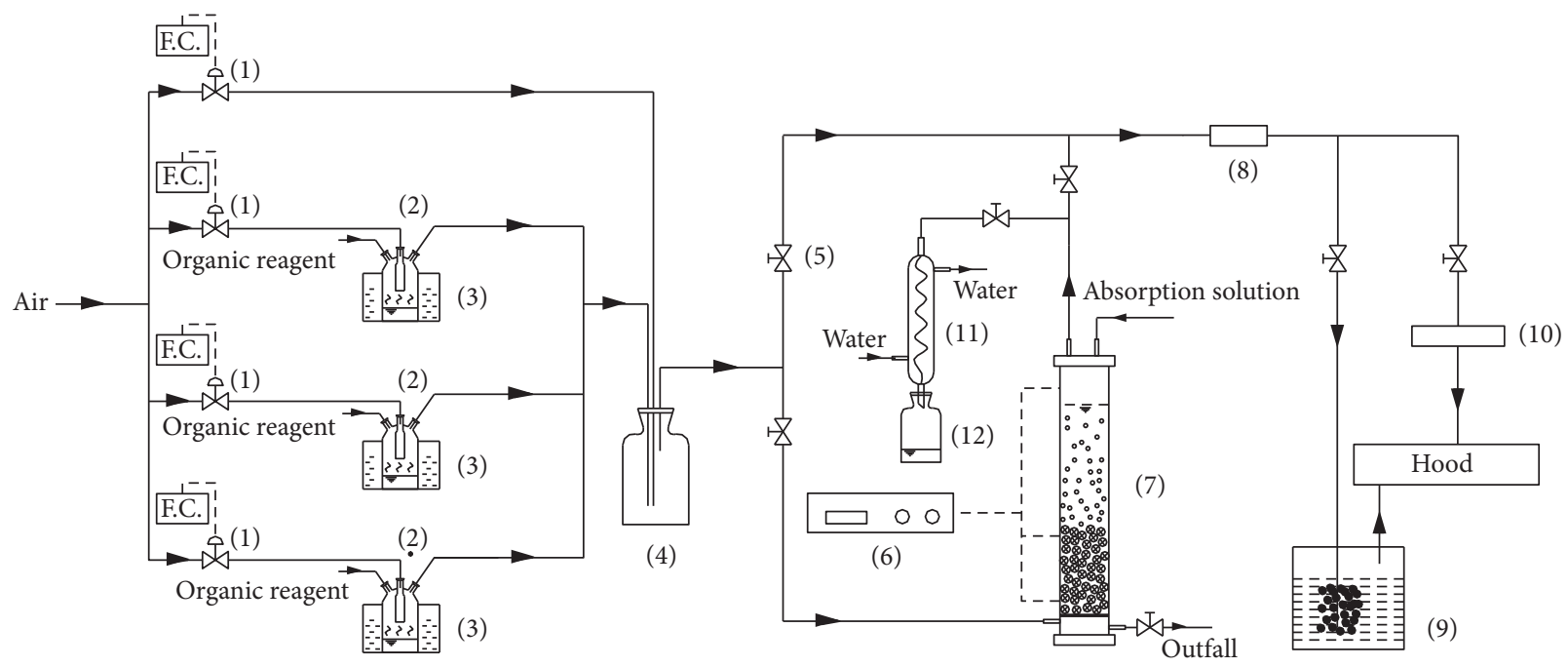

FIGURE 1: Schematic diagram of the experimental apparatus. (1) Mass flow controller; (2) VOC generator; (3) low temperature circulating water bath; (4) gas mixing bottle; (5) valve; (6) temperature controller and indicator; (7) absorption reactor; (8) dryer; (9) activated carbon; (10) gas analyzer; (11) serpentine condenser; (12) bottle.

of VOCs in the inlet and outlet were measured by a gaschromatograph (Agilent $6890 \mathrm{~N}$, Agilent Technologies Inc., USA) coupled with a flame ionization detector and a portable digital PID VOC detector (ppbRAE 3000, RAE Systems Inc., USA) coupled with a PID sensor equipped with a $10.6 \mathrm{eV}$ lamp. In order to protect the gas analyzer, a dryer was used to remove the moisture content in simulated organic waste gas. Finally, the vent gas was adsorbed by activated carbon.

As shown in Figure 1, the absorption solution was regenerated through heating at $100^{\circ} \mathrm{C}$ for $0.5 \mathrm{~h}$ for $1 \mathrm{run}$, and no gas was introduced into the absorption reactor during the regeneration. The toluene vapor entered the serpentine condenser where toluene was cooled until it condensed into a liquid, then the toluene liquid was collected in a glass bottle. Some amount of water would be lost due to evaporation during regeneration process, so it was necessary to add fresh water to prepare $1 \mathrm{~L}$ of the absorption solution after the regeneration, then the second experiment could be carried out.

Surface tension and interfacial tension of liquid were measured by the surface/interfacial tension meter (DCAT21, Dataphysics Instrument Co., Ltd. Germany). The temperature of the heating belt was regulated by the Al-518P artificial intelligence temperature controller (Electrical Automation Technology Co., Ltd., Xiamen Yu, China). A pH-electrode (PHS-3C, INESA Scientific Instrument Co., Ltd. Shang Hai, China) was immersed into the liquid to measure the $\mathrm{pH}$ value.

The percent of VOCs absorption efficiency was determined by the following equation:

$$
E(\%)=\frac{C_{\text {in }}-C_{\text {out }}}{C_{\text {in }}} \times 100
$$

where $E$ is the VOCs absorption efficiency and $C_{\text {in }}$ and $C_{\text {out }}$ are the VOCs concentration in the inlet and outlet gas, respectively.

\section{Results and Discussion}

3.1. Choice of Absorption Solution. In this study, several common solutions such as polyethylene glycol $(5 \%, \mathrm{v} / \mathrm{v})$, paraffin $(5 \%, v / v)$, tween $80(0.1 \%, \mathrm{w} / \mathrm{v})$, DMSO $(50 \%, \mathrm{v} / \mathrm{v})$, and tap water were used to remove toluene and compared with the PSW-5 absorption. It is worth to note that serious foaming problem was caused when the concentration of tween 80 was more than $0.1 \%(\mathrm{w} / \mathrm{v})$, so its concentration was $0.1 \%(\mathrm{w} / \mathrm{v})$ in this experiment. Both absorption temperature $\left(25^{\circ} \mathrm{C}\right)$ and toluene concentration $\left(1650 \mathrm{mg} \cdot \mathrm{L}^{-1}\right)$ were stable. The results are shown in Figure 2. It can be seen that the toluene absorption efficiencies of six kinds of absorbents all decreased by time due to the gradual saturation of absorbents. As the absorption continued, the toluene concentration in the absorbent was raised, leading to the absorption efficiency decrease. As shown in Figure 2, the water had lowest absorption efficiency and shortest saturation time for hydrophobic and nonpolar toluene. So water is not a suitable absorbent for hydrophobic and nonpolar VOCs removal in industry. Compared with water, other absorbents all could promote the absorption of toluene. Toluene absorption capacity of six kinds of absorbents was PSW-5 > DMSO > paraffin > polyethylene glycol $>$ tween $80>$ water, with the average absorption efficiencies of $90.77 \%, 72.41 \%, 57.28 \%, 33.73 \%$, $27.57 \%$, and $10.77 \%$, respectively. So, PSW appears clearly to be better absorbent than others as it has high capacity of toluene absorption; meanwhile, it has low production cost and high security. Therefore, PSW is a very attractive absorbent for controlling VOCs.

3.2. Effect of PSW Concentration. PSW concentration is an important effect factor to toluene absorption; it can be seen from Figure 3 that the toluene absorption efficiencies increased with the increment of PSW concentration. A sharp increase in toluene absorption efficiency from $55.54 \%$ to 
TABLE 1: Surface tension and interfacial tension between toluene and PSW at $25^{\circ} \mathrm{C}$.

\begin{tabular}{lcccccc}
\hline Concentrations of PSW $(\mathrm{v} / \mathrm{v})$ & $0.5 \%$ & $1.0 \%$ & $3.0 \%$ & $5.0 \%$ & $7.0 \%$ & $10.0 \%$ \\
\hline Surface tension $\left(\mathrm{mN} \cdot \mathrm{m}^{-1}\right)$ & $37.526 \pm 0.030$ & $37.126 \pm 0.023$ & $36.945 \pm 0.024$ & $36.651 \pm 0.026$ & $36.572 \pm 0.027$ & $36.489 \pm 0.030$ \\
Interfacial tension $\left(\mathrm{mN} \cdot \mathrm{m}^{-1}\right)$ & $17.493 \pm 0.014$ & $16.541 \pm 0.010$ & $16.127 \pm 0.015$ & $15.299 \pm 0.007$ & $13.987 \pm 0.011$ & $13.684 \pm 0.005$ \\
\hline
\end{tabular}

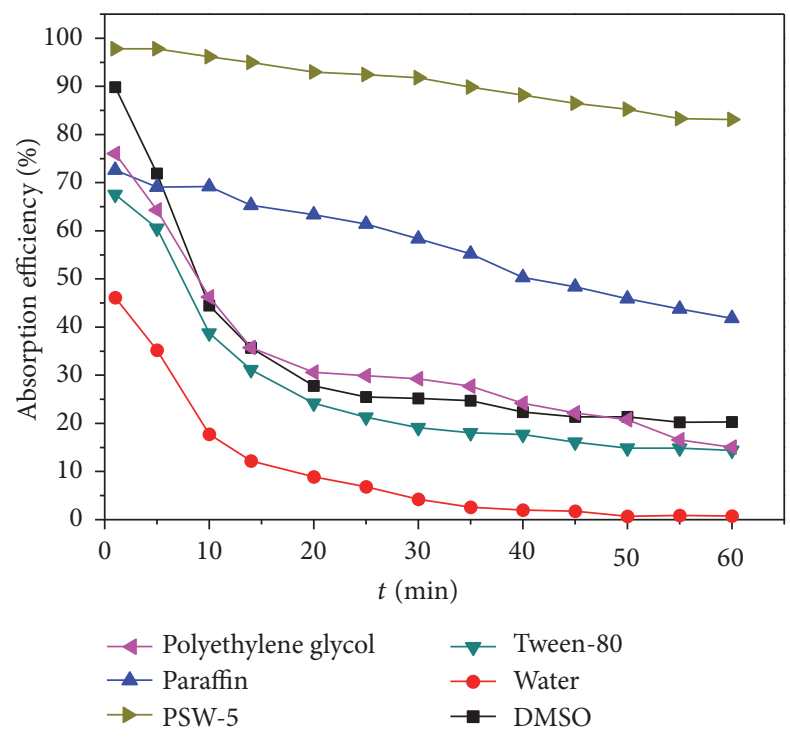

Figure 2: The effect of absorbents on toluene absorption efficiency. $Q_{\text {gas }}=1 \mathrm{~L} \cdot \mathrm{min}^{-1}, T_{\text {absorption }}=25^{\circ} \mathrm{C}$, and [toluene] $=1650 \mathrm{mg} \cdot \mathrm{m}^{-3}$.

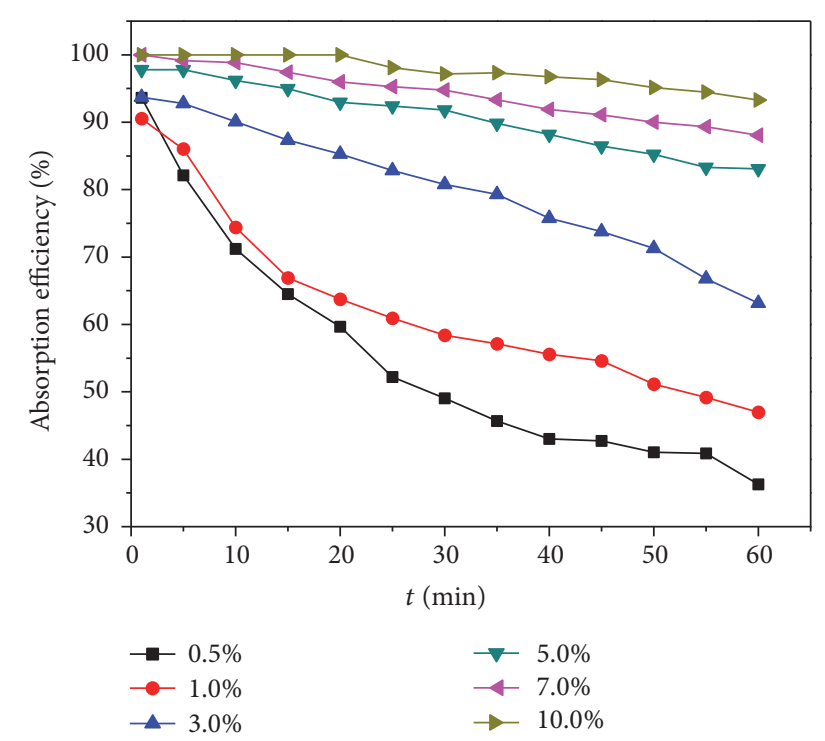

Figure 3: The effect of PSW concentration on toluene absorption efficiency. $Q_{\text {gas }}=1 \mathrm{~L} \cdot \mathrm{min}^{-1}, T_{\text {absorption }}=25^{\circ} \mathrm{C}$, initial $\mathrm{pH}=7.5$, and [toluene $=1650 \mathrm{mg} \cdot \mathrm{m}^{-3}$.

90.77\% was observed when the concentration varied from $0.5 \%$ to $5 \%(\mathrm{v} / \mathrm{v})$. This is because the increase of PSW concentration can increase the nonpolarity of absorption solution and cause higher absorption efficiency towards nonpolar VOCs.

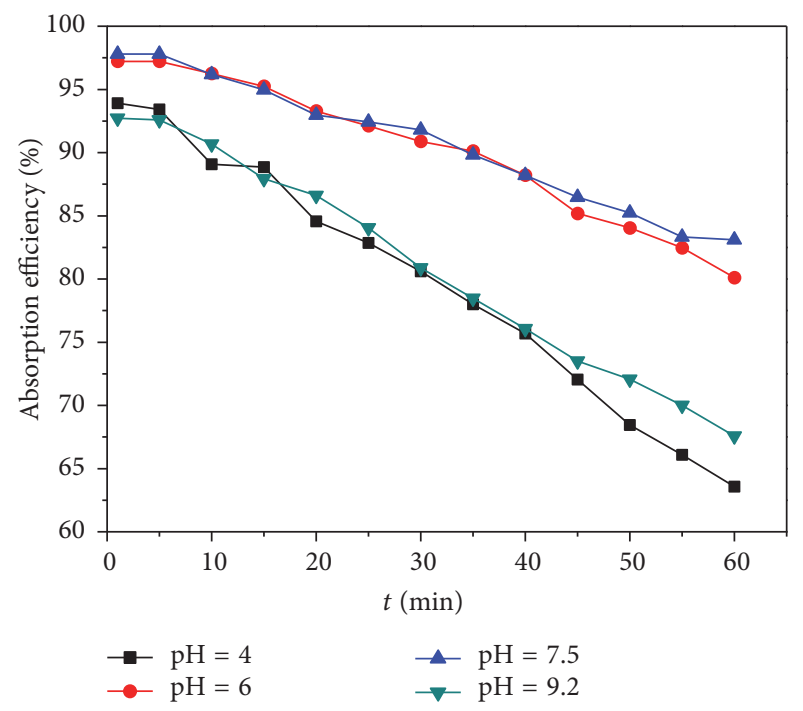

FIGURE 4: The effect of initial pH on toluene absorption efficiency. $Q_{\text {gas }}=1 \mathrm{~L} \cdot \mathrm{min}^{-1}, T_{\text {absorption }}=25^{\circ} \mathrm{C},[\mathrm{PSW}]=5 \%(\mathrm{v} / \mathrm{v})$, and [toluene] $=1650 \mathrm{mg} \cdot \mathrm{m}^{-3}$.

As listed in Table 1, the values of surface tension and interfacial tension between toluene and PSW decrease with the increase of PSW concentration. So the higher concentration of PSW can effectively promote the toluene absorption and lead to a high absorption efficiency of toluene. When the PSW concentration continued to increase, the absorption efficiency was still increasing, but the rate of increase of toluene absorption efficiency became slow. For example, when the PSW concentration increased from $5 \%$ to $10 \%(\mathrm{v} / \mathrm{v})$, toluene absorption efficiency increased only from $90.77 \%$ to about $97.58 \%$. It is speculated that the constant of gas-liquid contact time is the main cause of this phenomenon. Considering the pollutant emission concentration, pollutant emission standard, PSW costs, and security, PSW concentration in this study was selected as $5 \%(\mathrm{v} / \mathrm{v})$.

3.3. Effect of Initial pH of PSW. Organic waste gas emitted by certain industries contains acidic substances in actual production, or the water for preparation of solution is acidic or alkaline; these factors will lead to changes in the absorption solution $\mathrm{pH}$, thereby affecting the VOCs absorption. In this study, the initial pH of PSW-5 was 7.5, and the $\mathrm{pH}$ was adjusted to the desired value by adding $\mathrm{HCl}$ or $\mathrm{NaOH}$.

As shown in Figure 4, $\mathrm{pH}$ is one of important effect factors to toluene absorption. When the initial pH of PSW-5 changed from 4 to 6 , toluene absorption efficiency sharply increased from $79.78 \%$ to $90.17 \%$, then almost retained stable when solution $\mathrm{pH}$ varied from 6.0 to 7.5 , and thereafter decreased 


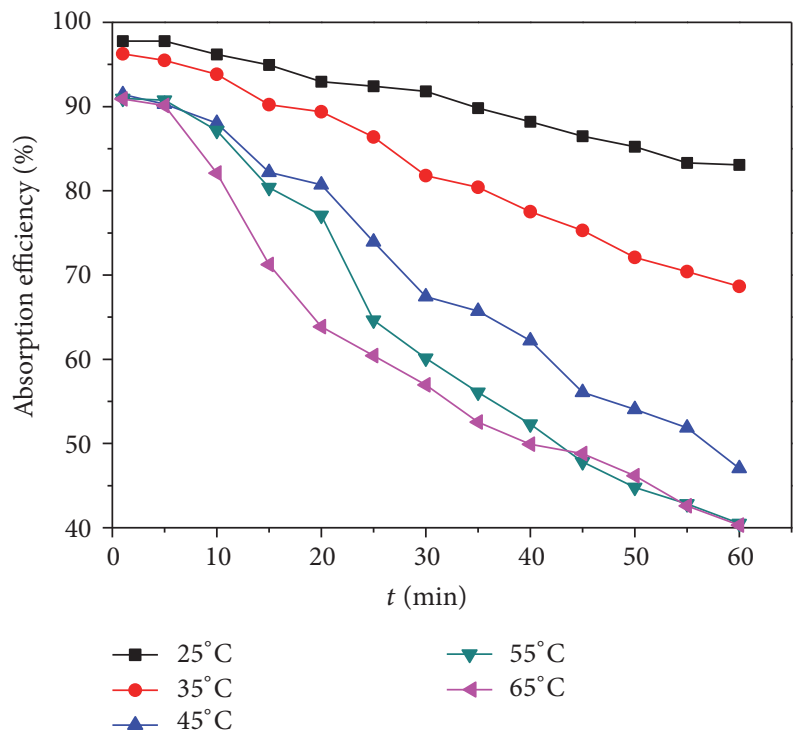

FIGURE 5: The effect of temperature on toluene absorption efficiency. $Q_{\text {gas }}=1 \mathrm{~L} \cdot \mathrm{min}^{-1}$, initial $\mathrm{pH}=7.5,[\mathrm{PSW}]=5 \%(\mathrm{v} / \mathrm{v})$, and [toluene $]=$ $1650 \mathrm{mg} \cdot \mathrm{m}^{-3}$.

with an increase of solution $\mathrm{pH}$ between 7.5 and 9.2. This is because the polarity of PSW-5 increases with the increase of initial $\mathrm{pH}$ in the alkaline solution and the decrease of initial $\mathrm{pH}$ in the acidic solution; meanwhile, strong acid or alkali conditions will reduce the stability of emulsion, leading to decrease of the toluene removal. Based on the consideration of equipment corrosion problems and industrial application to water scrubbers process, the optimal $\mathrm{pH}$ range of PSW-5 was selected as 6.0-7.5, and the optimal $\mathrm{pH}$ value was selected as 7.5 in this study.

3.4. Effect of Temperature. Figure 5 presents the effects of absorption temperature on the toluene absorption efficiency. It could be seen that the toluene absorption efficiency rapidly decreased with increasing the absorption temperature and then decreased slowly. This indicates that the PSW-5 is very sensitive to temperature, and the increase of absorption temperature is not conducive to the toluene removal. When the reaction temperatures were $25^{\circ} \mathrm{C}, 35^{\circ} \mathrm{C}, 45^{\circ} \mathrm{C}, 55^{\circ} \mathrm{C}$, and $65^{\circ} \mathrm{C}$, the average absorption efficiencies of toluene were $90.77 \%, 82.90 \%, 70.08 \%, 64.27 \%$, and $61.22 \%$, respectively. And from $25^{\circ} \mathrm{C}$ to $45^{\circ} \mathrm{C}$ the toluene absorption efficiency dropped more than 20 percentage points. This is because the solubility of toluene in PSW-5 decreases as the temperature is increased. Meanwhile, according to Henry's law, when the temperature increases Henry's constant will increase. So, when the toluene concentration in flow is stable, the toluene concentration in outlet gas will decrease. Therefore, when the absorption temperature increases the toluene absorption capacity of PSW decreases.

3.5. Effect of Toluene Concentration. The effect of toluene concentration on absorption efficiencies of toluene is shown in Figure 6. The results show that the toluene absorption

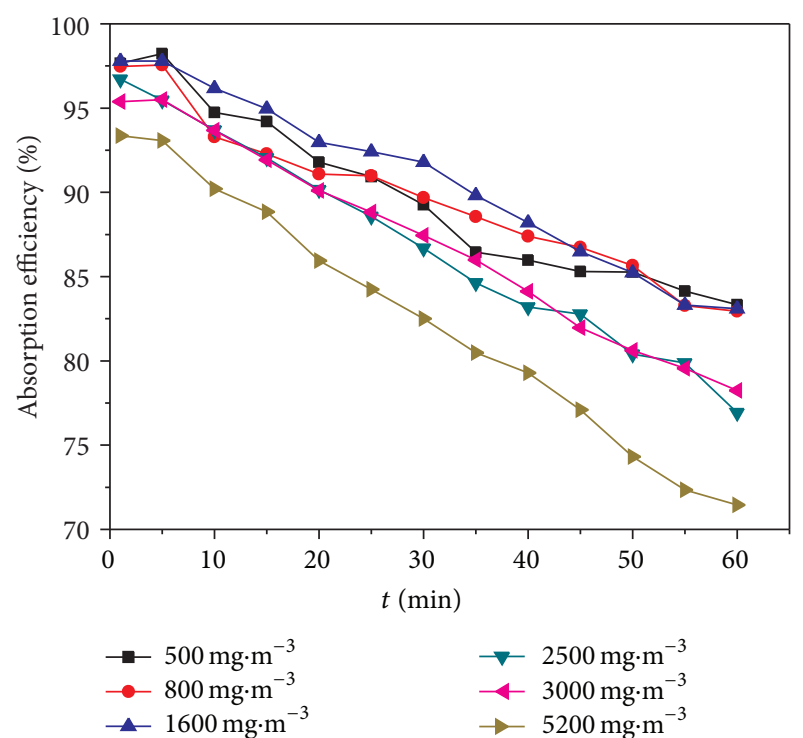

FIGURE 6: The effect of toluene concentration on toluene absorption efficiency. $Q_{\text {gas }}=1 \mathrm{~L} \cdot \mathrm{min}^{-1}, T_{\text {absorption }}=25^{\circ} \mathrm{C}$, initial $\mathrm{pH}=7.5$, and $[\mathrm{PSW}]=5 \%(\mathrm{v} / \mathrm{v})$.

efficiencies decreased slightly with the increase of toluene concentration, and all exceeded $80 \%$ where the inlet concentration of toluene varied from $500 \mathrm{mg} \cdot \mathrm{m}^{-3}$ to $5200 \mathrm{mg} \cdot \mathrm{m}^{-3}$. So the toluene absorption efficiency is slightly affected by toluene concentration. The gas phase driving force for mass transfer increases with increasing partial pressure of VOC in the inlet gas, so the absorption rate and the absorbed amount of toluene increase. Meanwhile, in this study the usage amount of paraffin/surfactant/water emulsion in the PSW-5 was excessive, so the toluene absorption efficiency was little changed relative to the changes of inlet toluene concentration. However, due to the fixed size of interfacial area between the gas and the liquid and a constant PSW concentration, whenever the concentration of toluene in the inlet gas is increased a limited amount of toluene in a fixed volume of absorbent is absorbed at a constant temperature. So, the PSW is an effective absorbent for removing VOCs from exhaust gas with a larger concentration range.

3.6. Effect of Gas Flow Rate. Figure 7 displays the effect of the gas flow rate on the absorption efficiency of toluene in the range from 0.5 to $3 \mathrm{~L} \cdot \mathrm{min}^{-1}$. Results show that the absorption efficiency of toluene is significantly affected by gas flow rate, and absorption efficiency of toluene reduces with increasing gas flow rate. When the gas flow rate varied from 0.5 to $3 \mathrm{~L} \cdot \mathrm{min}^{-1}$, the average absorption efficiencies of toluene were $96.60 \%, 90.77 \%, 76.98 \%, 69.94 \%$, and $57.24 \%$, respectively. The reason for such a decrease in absorption efficiency is the reduction of gas-liquid contact time. The gasliquid contact time decreases with the increase of the gas flow rate and results in the fact that the toluene molecules in the gas cannot have necessary time to dissolve in the PSW5. Therefore, higher amounts of toluene molecules leave the absorption reactor without absorption, and the absorption 
TABLE 2: Physical and chemical properties of common VOCs.

\begin{tabular}{|c|c|c|c|c|c|c|c|c|}
\hline Compound & Formula & $\begin{array}{c}\text { Molecular } \\
\text { weight } \\
\left(\mathrm{g} \cdot \mathrm{mol}^{-1}\right)\end{array}$ & $\begin{array}{l}\text { Relative } \\
\text { density } \\
\left(\mathrm{g} \cdot \mathrm{cm}^{-3}\right)\end{array}$ & $\begin{array}{l}\text { Boiling point } \\
\quad\left({ }^{\circ} \mathrm{C}\right)\end{array}$ & $\begin{array}{l}\text { Melting point } \\
\left({ }^{\circ} \mathrm{C}\right)\end{array}$ & $\begin{array}{l}\text { Logarithm of } \\
\text { the } \\
\text { octanol/water } \\
\text { partition } \\
\text { coefficient }\end{array}$ & $\begin{array}{l}\text { Saturated } \\
\text { vapor } \\
\text { pressure } \\
(\mathrm{Kpa})\end{array}$ & Polarity \\
\hline Benzene & $\mathrm{C}_{6} \mathrm{H}_{6}$ & 78.11 & 0.8765 & 80.1 & 5.5 & 2.15 & $\begin{array}{c}26.66 \\
\left(31.6^{\circ} \mathrm{C}\right)\end{array}$ & 3.0 \\
\hline Toluene & $\mathrm{C}_{7} \mathrm{H}_{8}$ & 92.14 & 0.8636 & 110.6 & -94.9 & 2.69 & $4.89\left(30^{\circ} \mathrm{C}\right)$ & 2.4 \\
\hline Xylene & $\mathrm{C}_{8} \mathrm{H}_{10}$ & 106.16 & 0.880 & 144.4 & -25 & 3.12 & $1.33\left(32^{\circ} \mathrm{C}\right)$ & 2.5 (p-xylene) \\
\hline Acetone & $\mathrm{C}_{3} \mathrm{H}_{6} \mathrm{O}$ & 58.08 & 0.797 & 56.48 & -94.6 & -0.24 & $37.69\left(30^{\circ} \mathrm{C}\right)$ & 5.4 \\
\hline Ethyl acetate & $\mathrm{C}_{4} \mathrm{H}_{8} \mathrm{O}_{2}$ & 88.10 & 0.90 & 77.2 & -83.6 & 0.73 & $13.33\left(27^{\circ} \mathrm{C}\right)$ & 4.3 \\
\hline Hexane & $\mathrm{C}_{6} \mathrm{H}_{14}$ & 86.17 & 0.659 & 68.7 & -95.6 & 3.9 & $17\left(20^{\circ} \mathrm{C}\right)$ & 0.06 \\
\hline Water & $\mathrm{H}_{2} \mathrm{O}$ & 18.02 & 1 & 100 & 0 & - & $2.34\left(20^{\circ} \mathrm{C}\right)$ & 10.20 \\
\hline
\end{tabular}

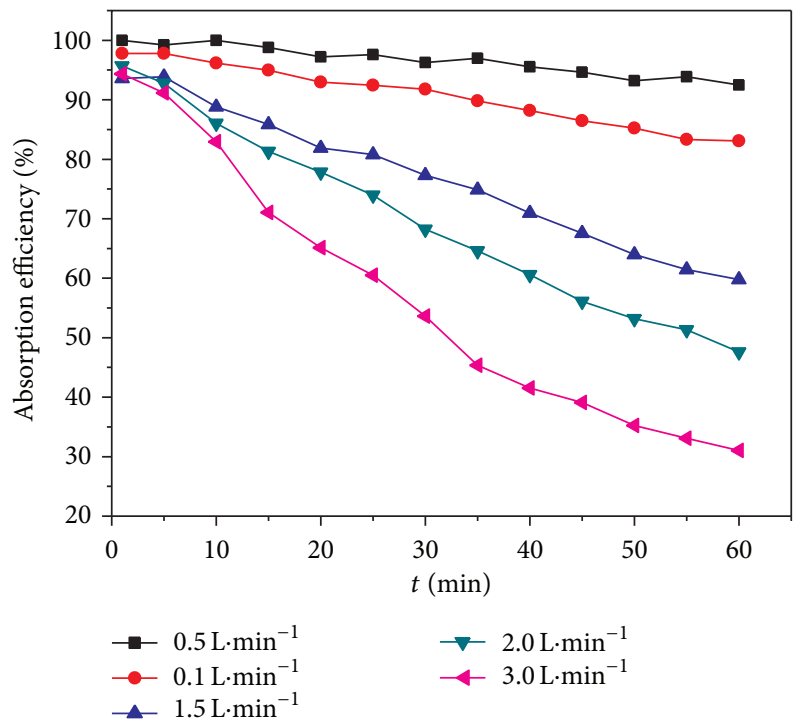

FIGURE 7: The effect of gas flow rate on toluene absorption efficiency. $T_{\text {absorption }}=25^{\circ} \mathrm{C}$, initial $\mathrm{pH}=7.5,[\mathrm{PSW}]=5 \%(\mathrm{v} / \mathrm{v})$, and [toluene $]=$ $1650 \mathrm{mg} \cdot \mathrm{m}^{-3}$.

efficiency of toluene reduces with increasing gas flow rate. However, the absolute amount of the toluene absorbed by the PSW-5 increases with the increase of the gas flow rate at a constant temperature.

3.7. Effect of Species of VOCs. There are many species of VOCs emitted from industry. Major VOCs include aromatics, alkanes, ketones, and esters. There are different absorbing performances of absorbent on different VOCs at constant conditions in the actual production. So, in this study benzene, toluene, xylene, ethyl acetate, hexane, and acetone were chosen as representative of VOCs, absorbing performances of PSW-5 on them were observed, and the result is shown in Figure 8 .

It can be seen from Figure 8 that absorption capacity of PSW for six kinds of VOCs is acetone $>$ ethyl acetate $>$ xylene $>$ toluene $>$ benzene $>$ hexane, with the average absorption

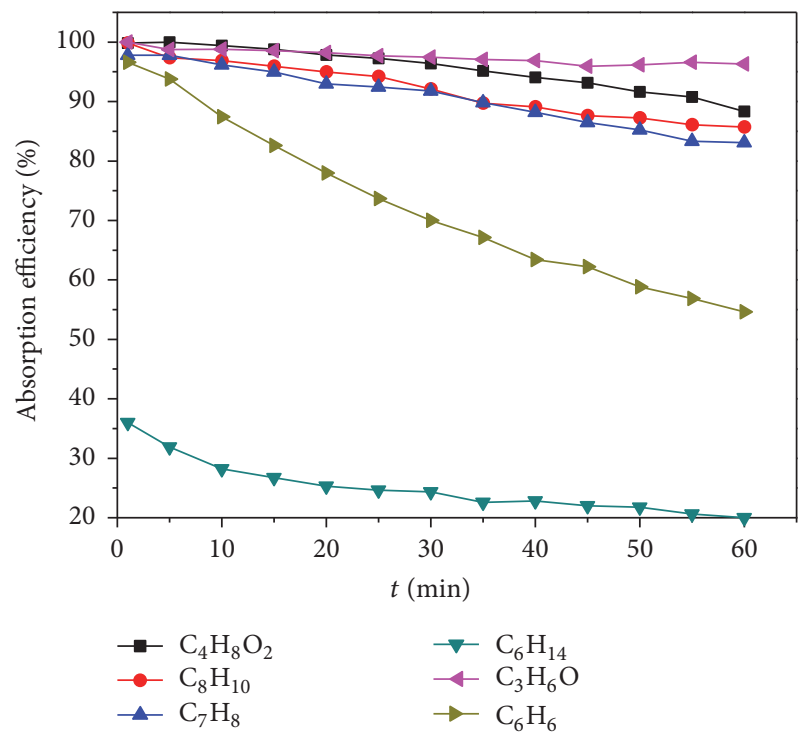

FIGURE 8: The absorbing performances of PSW on different VOCs. $Q_{\text {gas }}=1 \mathrm{~L} \cdot \mathrm{min}^{-1}, T_{\text {absorption }}=25^{\circ} \mathrm{C}$, initial $\mathrm{pH}=7.5,[\mathrm{PSW}]=5 \%(\mathrm{v} / \mathrm{v})$, [acetone $]=1600 \mathrm{mg} \cdot \mathrm{m}^{-3}$, [ethyl acetate $]=1570 \mathrm{mg} \cdot \mathrm{m}^{-3},[$ xylene $]=$ $1800 \mathrm{mg} \cdot \mathrm{m}^{-3}$, [toluene] $=1650 \mathrm{mg} \cdot \mathrm{m}^{-3}$, [benzene] $=1500 \mathrm{mg} \cdot \mathrm{m}^{-3}$, and [hexane] $=1550 \mathrm{mg} \cdot \mathrm{m}^{-3}$.

efficiencies of $97.58 \%$, 95.59\%, 92.06\%, 90.77\%, 72.71\%, and $25.14 \%$, respectively. It suggests that the absorption efficiencies of ketones, esters, and aromatics are much higher than the absorption efficiencies of alkanes when PSW is used as the absorbent.

The differences of absorbing performances depend on the physical and chemical properties of VOCs when the temperature and partial pressure of VOC are kept constant. Solubility and diffusivity of VOCs are major physical properties that affect the absorption of VOCs. Chemical properties, such as polarity of VOCs and liquids, and hydrophobic or hydrophilic nature of VOCs all can affect the absorption efficiency. The physical and chemical properties of six kinds of VOCs are listed in Table 2, combined with the results of absorption experiments; the following conclusions can 
TABle 3: Toluene solubility, $P_{\text {sat }}$, Henry's constant,and activity coefficientvalues at $25^{\circ} \mathrm{C}$.

\begin{tabular}{lcccccc}
\hline & Solubility $\left(\mathrm{g} \cdot \mathrm{L}^{-1}\right)$ & $P_{\text {sat }}(\mathrm{pa})$ & $H$ & $H^{*}\left(\mathrm{~Pa} \cdot \mathrm{m}^{3} \cdot \mathrm{mol}^{-1}\right)$ & $H^{* *}(\mathrm{Kpa})$ & 316.75 \\
\hline PSW & 1.331 & 82.46 & 0.0023 & 5.70 & 3841.26 \\
Water & 0.53 & 3803 & 0.2663 & 660.14 & 55561.32 & 14609.87 \\
\hline
\end{tabular}

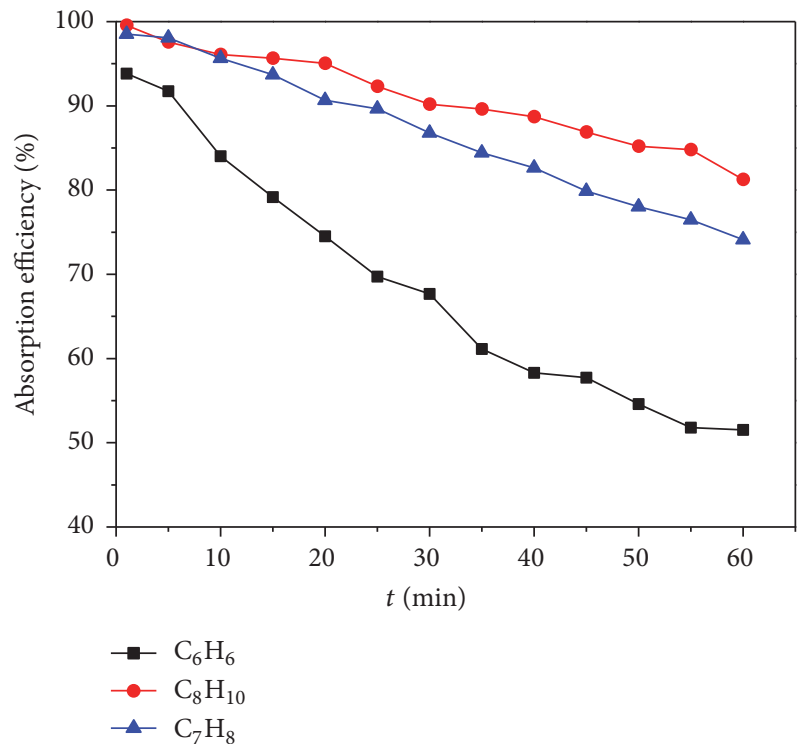

FIGURE 9: The absorbing performances of PSW on multicomponent VOCs. $Q_{\text {gas }}=1 \mathrm{~L} \cdot \mathrm{min}^{-1}, T_{\text {absorption }}=25^{\circ} \mathrm{C}$, initial $\mathrm{pH}=7.5$, $[\mathrm{PSW}]=$ $5 \%(\mathrm{v} / \mathrm{v}),[$ xylene $]=1800 \mathrm{mg} \cdot \mathrm{m}^{-3}$, [toluene] $=1650 \mathrm{mg} \cdot \mathrm{m}^{-3}$, and [benzene] $=1500 \mathrm{mg} \cdot \mathrm{m}^{-3}$.

be got. (1) For different types of organic matter, the absorption efficiency generally increases with the increase of the molecular polarity and the decrease of logarithm of the octanol/water partition coefficient of VOCs. (2) For the same type of hydrophobic VOCs, such as benzene series, the larger saturated vapor pressure of VOCs, the lower absorption efficiency achieved, and the absorption efficiency generally increases with the increase of logarithm of the octanol/water partition coefficient of VOCs. (3) The absorption efficiencies of hydrophilic VOCs are better than that of hydrophobic VOCs. (4) Most hydrophobic and hydrophilic VOCs can be effectively removed by PSW.

As Figure 9 illustrates, when the inlet gas also contained benzene, toluene, and xylene, the average absorption efficiencies of xylene, toluene, and benzene were 90.99\%, 86.81\%, and $68.90 \%$, respectively. Compared with single contaminant removal (Figure 8), the absorption efficiencies of three kinds of VOCs all declined in varying degrees. This is because there is competition between different organic molecules in the absorption process. However, the absolute amount of the VOCs transferred from gas into PSW-5 increases. The results also indicate that the VOCs absorption efficiency is slightly affected by composition of VOCs.

3.8. Breakthrough Experiment. Figure 10 shows the breakthrough curves of toluene under the experimental conditions.

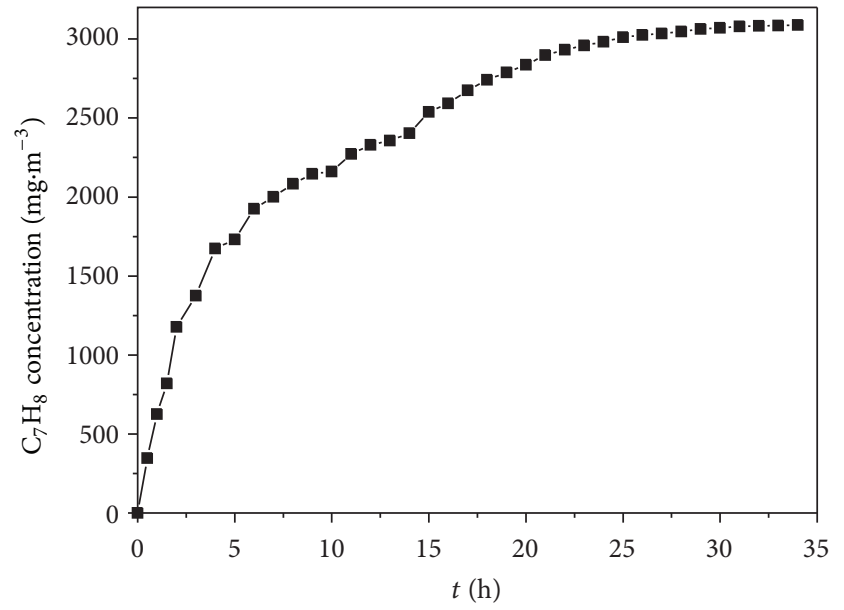

Figure 10: The breakthrough curves of toluene. $Q_{\text {gas }}=1 \mathrm{~L} \cdot \mathrm{min}^{-1}$, $T_{\text {absorption }}=25^{\circ} \mathrm{C}$, initial $\mathrm{pH}=7.5,[\mathrm{PSW}]=5 \%(\mathrm{v} / \mathrm{v})$, and [toluene $]=$ $3100 \mathrm{mg} \cdot \mathrm{m}^{-3}$.

As demonstrated in Figure 10, the toluene concentration in outlet gas slowly increased with the increase of absorption time, and the equilibrium was reached after $34 \mathrm{~h}$. According to the mass balance, toluene concentration in the liquid phase can be calculated by using integration method, and the value $\left(C_{l}\right)$ is $1331 \mathrm{mg} \cdot \mathrm{L}^{-1}$. Then, dimensionless Henry's constant $(H)$ could be calculated by (2) [27], Henry's constant $\left(H^{*}\right)$ and $\left(H^{* *}\right)$ could be calculated by (3) and (4), respectively [11], and the activity coefficient $\gamma$ is defined by (5) [18], and the results are shown in Table 3.

$$
\begin{aligned}
H C_{l} & =C_{g} \\
H^{*} & =H R T \\
H^{* *} & =\frac{H^{*} c_{t}}{x_{t}} \\
\gamma & =\frac{H^{* *}}{P_{\mathrm{sat}}},
\end{aligned}
$$

where $R$ and $T$ are the constant of perfect gas and the absorption temperature, respectively, $c_{t}$ is the concentration of toluene, $x_{t}$ is the mole fraction of toluene, and $P_{\text {sat }}$ is the saturation pressure of the toluene.

The value of Henry's constant gives the composition of the liquid which would be in thermodynamic balance with the inlet gas. $\gamma$ is characteristic of the interaction between toluene and the absorbent. Generally, the smaller the Henry's constant and the activity coefficient value, the greater the solubility of VOCs. As exhibited in Table 3, Henry's constant value of toluene in PSW-5 is more than 115 times lower 


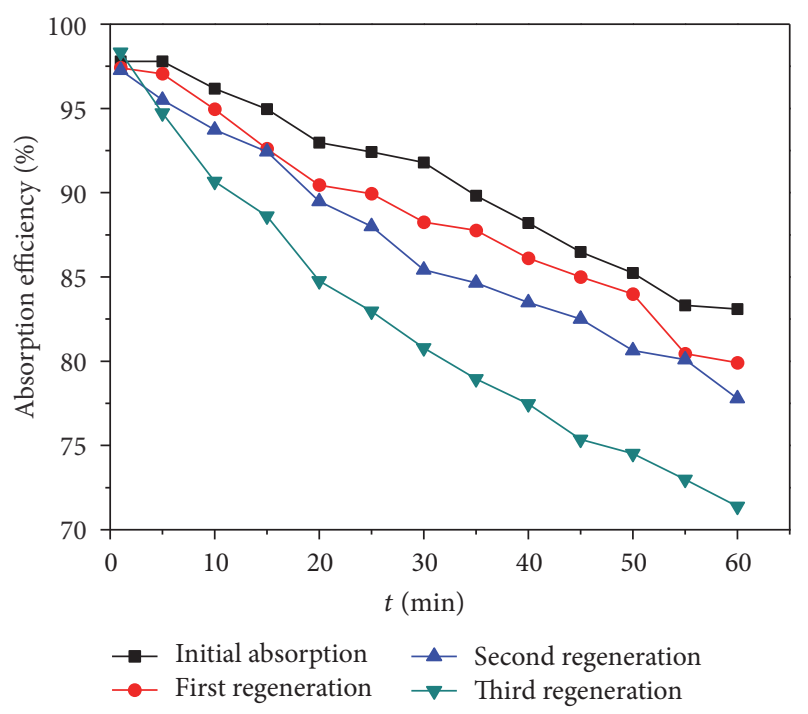

FIGURE 11: The effect of regeneration on toluene absorption efficiency. $Q_{\text {gas }}=1 \mathrm{~L} \cdot \mathrm{min}^{-1}, T_{\text {absorption }}=25^{\circ} \mathrm{C}$, initial $\mathrm{pH}=7.5,[\mathrm{PSW}]=$ $5 \%(\mathrm{v} / \mathrm{v})$, and [toluene] $=1650 \mathrm{mg} \cdot \mathrm{m}^{-3}$.

than the value in water, since a Henry's constant value of $316.75 \mathrm{kPa}$ is obtained, which should be compared to that of water, $55561.32 \mathrm{kPa}$. Meanwhile, the activity coefficient value of toluene in PSW-5 and the saturation pressure of the toluene all are significantly lower than those of water. Finally the toluene solubility in the PSW-5 is more than 2.5 times higher than the value in water. The results suggest that the PSW is more suitable for application as an effective VOCs absorbent.

3.9. Regeneration Experiment. The disposal of VOCs saturated absorbents is an important issue in industry, and it is also an important factor in limiting the absorption method for industrial application. Fortunately, the used absorbent regeneration could perfectly solve the problem. Figure 11 presents the variation of the absorption efficiencies of toluene with regeneration run. Results show that the absorption capacities of PSW-5 for toluene slightly decreased with increasing regeneration runs. After 3 runs of regeneration the absorption efficiency of PSW for toluene was $82.42 \%$, less than the initial absorption efficiency (90.77\%) of PSW-5. The decrease of the absorption efficiency is mainly ascribed to the evaporation of paraffin in the PSW because of heating. Consequently, present results show that the process can achieve the PSW reuse and organic recycling.

\section{Conclusions}

In this study, a new paraffin/surfactant/water emulsion for VOCs controlling was developed, and an evaluation of the influence of different experimental parameters on toluene absorption efficiency was carried out. The following conclusions can be listed considering the experimental data obtained: for a given VOC and process conditions, PSW5 provided higher absorption efficiency $(90.77 \%)$ than the other absorbents used. Compared with water, $P_{\text {sat }}, H$, and $\gamma$ of toluene in PSW-5 are significantly lower than those in water, and toluene solubility in PSW-5 is more than 2.5 times higher than the value in water. Toluene absorption efficiency can be increased by increasing the concentration of PSW or lowering the absorption temperature and gas flow rate, and the absorption efficiency is slightly affected by inlet concentration of toluene. $\mathrm{pH}$ is one of the important factors affecting the toluene absorption, toluene absorption efficiency increases with the increment of initial $\mathrm{pH}$ at first and then dropping with the rise of solution $\mathrm{pH}$, and the optimal $\mathrm{pH}$ value is 7.5. There are different absorbing performances of PSW on different VOCs at constant conditions, the absorption capacity of selected six kinds of VOCs is acetone $>$ ethyl acetate $>$ xylene $>$ toluene $>$ benzene $>$ hexane, and most VOCs can be effectively removed by PSW. Regeneration and reuse of the PSW are possible; after 3 runs of regeneration the absorption efficiency of PSW-5 for toluene also can reach $82.42 \%$. Absorptive removal of VOCs using the PSW can be a cost effective process for the industrial application.

\section{Competing Interests}

The authors declare that they have no competing interests.

\section{Acknowledgments}

This work was supported by the National Science and Technology Support Project (2014BAC21B04), the Guangdong Natural Science Foundation (2015A030310344), the Project of Science and Technology Program of Guangdong Province (2014A020216015, 2015A020220008, and 2015B020215008), the Pearl River S\&T Nova Program of Guangzhou (201610010150), and the special funds for research from the Environmental Charity Project (Grant PM-ZX021-201407-082).

\section{References}

[1] Z. X. Zhang, Z. Jiang, and W. F. Shangguan, "Low-temperature catalysis for VOCs removal in technology and application: a state-of-the-art review," Catalysis Today, vol. 264, pp. 270-278, 2016.

[2] R. Tatin, L. Moura, N. Dietrich, S. Baig, and G. Hébrard, "Physical absorption of volatile organic compounds by spraying emulsion in a spray tower: experiments and modelling," Chemical Engineering Research and Design, vol. 104, pp. 409-415, 2015.

[3] F. Heymes, P. M. Demoustier, F. Charbit, J. L. Fanlo, and P. Moulin, "Hydrodynamics and mass transfer in a packed column: case of toluene absorption with a viscous absorbent," Chemical Engineering Science, vol. 61, no. 15, pp. 5094-5106, 2006.

[4] K. Q. Qiu, L. X. Yang, J. M. Lin et al., "Historical industrial emissions of non-methane volatile organic compounds in China for the period of 1980-2010," Atmospheric Environment, vol. 86, pp. 102-112, 2014.

[5] M. S. Kamal, S. A. Razzak, and M. M. Hossain, "Catalytic oxidation of volatile organic compounds (VOCs) - a review," Atmospheric Environment, vol. 140, pp. 117-134, 2016.

[6] C.-C. Lin, Y.-C. Lin, and K.-S. Chien, "VOCs absorption in rotating packed beds equipped with blade packings," Journal of 
Industrial and Engineering Chemistry, vol. 15, no. 6, pp. 813-818, 2009.

[7] Y. Zhou, L. Zhou, X. H. Zhang, and Y. L. Chen, "Preparation of zeolitic imidazolate framework-8/graphene oxide composites with enhanced VOCs adsorption capacity," Microporous and Mesoporous Materials, vol. 225, pp. 488-493, 2016.

[8] B. Ozturk, C. Kuru, H. Aykac, and S. Kaya, "VOC separation using immobilized liquid membranes impregnated with oils," Separation and Purification Technology, vol. 153, pp. 1-6, 2015.

[9] F. I. Khan and A. K. Ghoshal, "Removal of volatile organic compounds from polluted air," Journal of Loss Prevention in the Process Industries, vol. 13, no. 6, pp. 527-545, 2000.

[10] M. Piumetti, D. Fino, and N. Russo, "Mesoporous manganese oxides prepared by solution combustion synthesis as catalysts for the total oxidation of VOCs," Applied Catalysis B: Environmental, vol. 163, pp. 277-287, 2015.

[11] I. Béchohra, A. Couvert, and A. Amrane, "Absorption and biodegradation of toluene: optimization of its initial concentration and the biodegradable non-aqueous phase liquid volume fraction," International Biodeterioration and Biodegradation, vol. 104, pp. 350-355, 2015.

[12] M. Ragazzi, P. Tosi, E. C. Rada, V. Torretta, and M. Schiavon, "Effluents from MBT plants: plasma techniques for the treatment of VOCs," Waste Management, vol. 34, no. 11, pp. 24002406, 2014.

[13] X. F. Qian, D. T. Yue, Z. Y. Tian et al., "Carbon quantum dots decorated $\mathrm{Bi}_{2} \mathrm{WO}_{6}$ nanocomposite with enhanced photocatalytic oxidation activity for VOCs," Applied Catalysis B: Environmental, vol. 193, pp. 16-21, 2016.

[14] M. Tokumura, R. Nakajima, H. T. Znad, and Y. Kawase, "Chemical absorption process for degradation of VOC gas using heterogeneous gas-liquid photocatalytic oxidation: toluene degradation by photo-Fenton reaction," Chemosphere, vol. 73, no. 5, pp. 768-775, 2008.

[15] J. M. Estrada, S. Hernández, R. Muñoz, and S. Revah, "A comparative study of fungal and bacterial biofiltration treating a VOC mixture," Journal of Hazardous Materials, vol. 250-251, pp. 190-197, 2013.

[16] B. Ozturk and D. Yilmaz, "Absorptive removal of volatile organic compounds from flue gas streams," Process Safety and Environmental Protection, vol. 84, no. 5, pp. 391-398, 2006.

[17] P. Blach, S. Fourmentin, D. Landy, F. Cazier, and G. Surpateanu, "Cyclodextrins: a new efficient absorbent to treat waste gas streams," Chemosphere, vol. 70, no. 3, pp. 374-380, 2008.

[18] F. Heymes, P. Manno-Demoustier, F. Charbit, J. L. Fanlo, and P. Moulin, "A new efficient absorption liquid to treat exhaust air loaded with toluene," Chemical Engineering Journal, vol. 115, no. 3, pp. 225-231, 2006.

[19] P.-F. Biard and A. Couvert, "Overview of mass transfer enhancement factor determination for acidic and basic compounds absorption in water," Chemical Engineering Journal, vol. 222, pp. 444-453, 2013.

[20] E. Dumont, G. Darracq, A. Couvert et al., "Volumetric mass transfer coefficients characterising VOC absorption in water/silicone oil mixtures," Chemical Engineering Journal, vol. 221, pp. 308-314, 2013.

[21] F. Lalanne, L. Malhautier, J.-C. Roux, and J.-L. Fanlo, "Absorption of a mixture of volatile organic compounds (VOCs) in aqueous solutions of soluble cutting oil," Bioresource Technology, vol. 99, no. 6, pp. 1699-1707, 2008.
[22] Z. Xiang, Y. Lu, X. Gong, and G. Luo, "Absorption and desorption of gaseous toluene by an absorbent microcapsules column," Journal of Hazardous Materials, vol. 173, no. 1-3, pp. 243-248, 2010.

[23] R. Hadjoudj, H. Monnier, C. Roizard, and F. Lapicque, "Measurements of diffusivity of chlorinated VOCs in heavy absorption solvents using a laminar falling film contactor," Chemical Engineering and Processing, vol. 47, no. 9-10, pp. 1478-1483, 2008.

[24] B. Park, G. Hwang, S. Haam, C. Lee, I.-S. Ahn, and K. Lee, "Absorption of a volatile organic compound by a jet loop reactor with circulation of a surfactant solution: performance evaluation," Journal of Hazardous Materials, vol. 153, no. 1-2, pp. 735-741, 2008.

[25] G. Darracq, A. Couvert, C. Couriol et al., "Silicone oil: an effective absorbent for the removal of hydrophobic volatile organic compounds," Journal of Chemical Technology and Biotechnology, vol. 85, no. 3, pp. 309-313, 2010.

[26] L. Liu, S. Tian, and P. Ning, "Phase behavior of TXs/toluene/water microemulsion systems for solubilization absorption of toluene," Journal of Environmental Sciences, vol. 22, no. 2, pp. 271-276, 2010.

[27] M.-D. Vuong, A. Couvert, C. Couriol, A. Amrane, P. Le Cloirec, and C. Renner, "Determination of the Henry's constant and the mass transfer rate of VOCs in solvents," Chemical Engineering Journal, vol. 150, no. 2-3, pp. 426-430, 2009. 

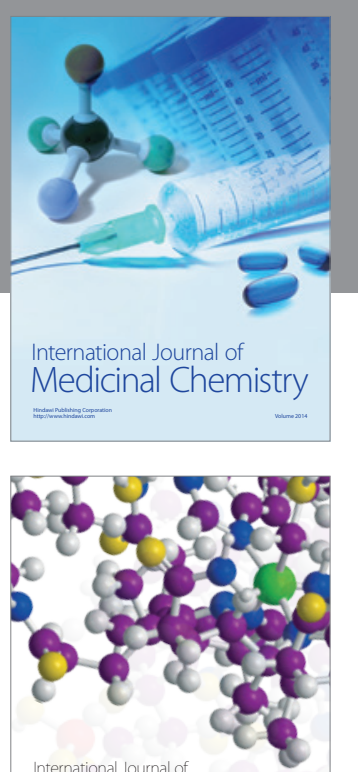

Carbohydrate Chemistry

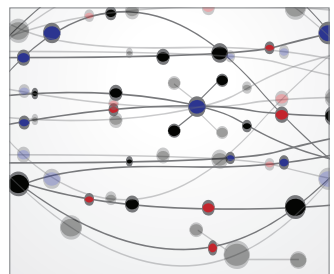

The Scientific World Journal
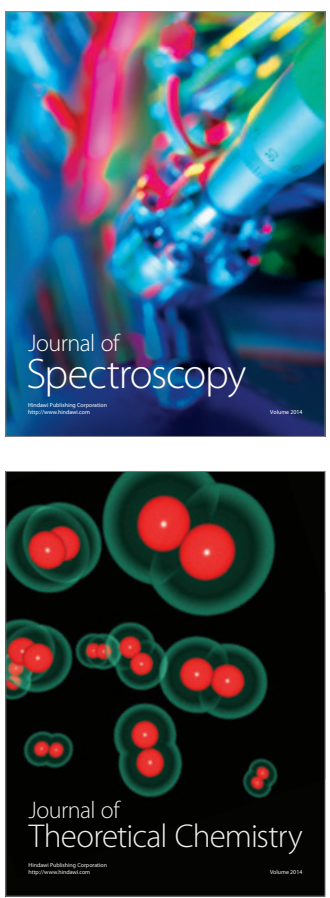
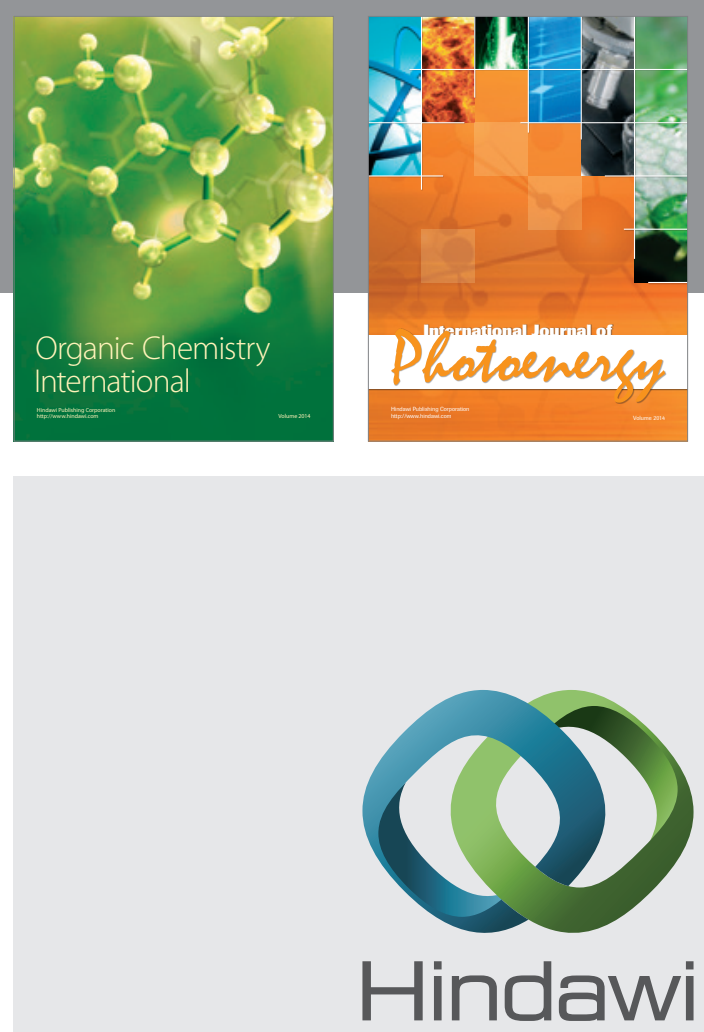

Submit your manuscripts at

http://www.hindawi.com

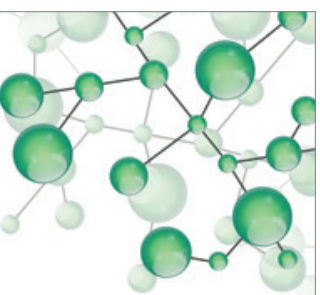

International Journal of

Inorganic Chemistry

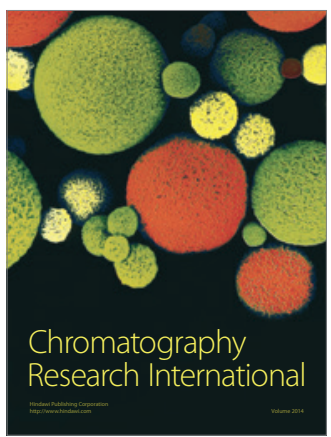

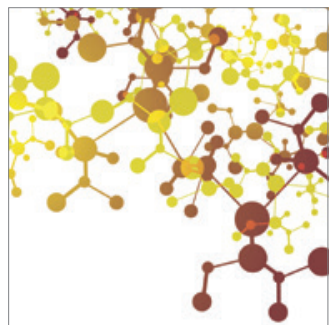

Applied Chemistry
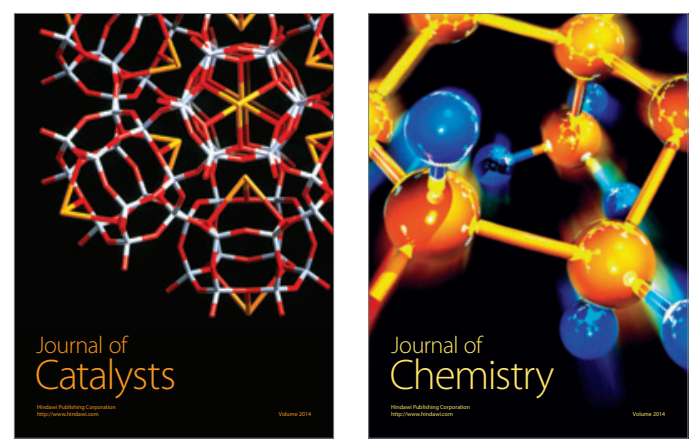
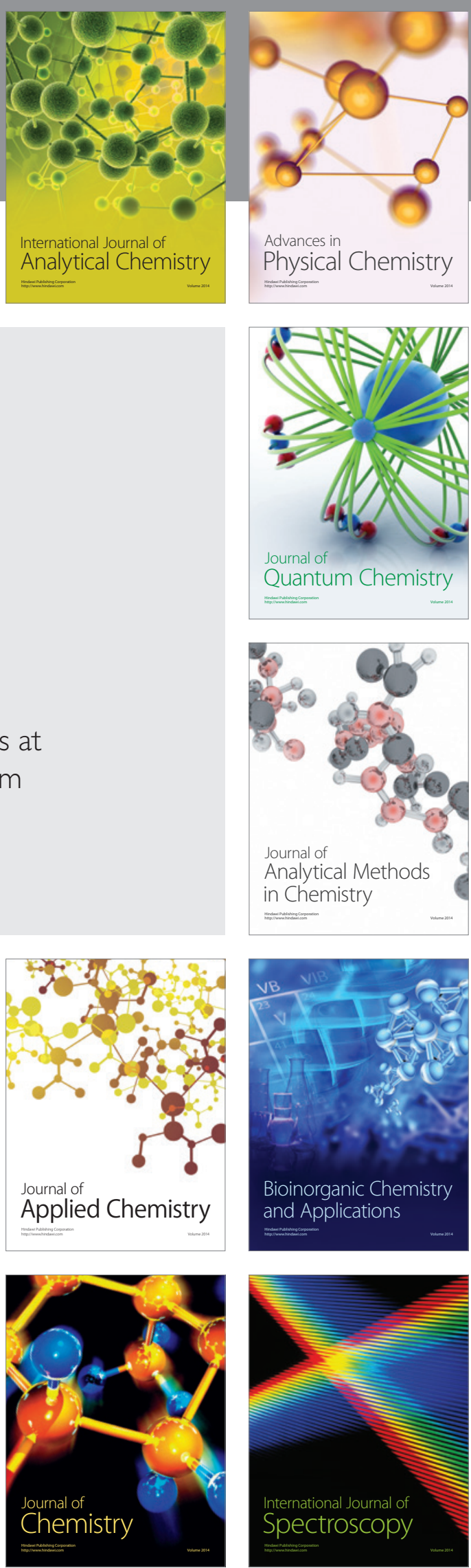